\title{
Taste tests: Impacts of consumer perceptions and preferences on brand positioning strategies
}

Received (in revised form): 1st March, 2001

\section{Dr Sanjoy Ghose}

is a full professor of marketing at the University of Wisconsin-Milwaukee, USA. He has a PhD in marketing from Carnegie-Mellon University, USA.

\section{Dr Oded Lowengart}

is a lecturer in the Department of Business Administration, School of Management, Ben-Gurion University of the Negev, Israel. $\mathrm{He}$ has a PhD in marketing from the University of Winsconsin-Milwaukee, USA.

\begin{abstract}
Taste tests are being increasingly used by marketers to influence consumers to change their preferences toward their brands. This research indicates how perceptual and preferential taste tests can be used in conjunction with visual maps to provide support to marketing managers for making better brand positioning and targeting decisions on the basis of taste for different segments of consumers. An empirical blind taste-test study is used to illustrate the concepts. The preferential taste judgment part of the empirical study is designed to capture violations of the 'Independence of Irrelevant Alternatives' (IIA) effect that is commonly observed in consumers' actual purchases. The present paper also uses a hypothetical example to indicate the importance of considering the location of consumer 'ideal points' before making formulation changes in a brand as part of a targeting strategy. Various managerial implications of using the suggested perceptual preferential taste-mapping analyses are also discussed. Appropriate measurements of consumer tastes provide insights for identifying and targeting viable market segments.
\end{abstract}

Dr Sanjoy Ghose School of Business Administration, University of Wisconsin-Milwaukee, PO Box 742, Milwaukee 53201, USA.

Tel: (1)-414-2294224; Fax: (1)-414-2296957; e-mail: sanjoy@uwm.edu

\section{INTRODUCTION}

Taste tests are a common activity of marketers in various industries. Such tests are major selling and advertising message design tools that are aimed at convincing potential customers about the superiority of one brand over another. In other words, taste test results are used by firms in targeting potential and existing markets.
The usefulness of these targeting strategies is clearly a function of how well marketing researchers are able to measure consumer feelings about the tastes of different brands. The focus of the present paper is to first evaluate the characteristics of some primary

approaches to measurements of consumer tastes. Next empirical data based on these different measurement methods and 
multidimensional scaling analysis are used to come up with spatial representations of brands and consumer segments. How the combination of taste measurements and spatial representations can be utilised to identify distinct market segments is then illustrated. The resultant composite information about the spatial locations of brands, their attributes and consumer segments will enable marketing managers to come up with an effective marketing strategy for targeting these segments.

Before discussing the suggested methodology, it is pertinent to consider some examples of the usage of taste tests in different product categories in various markets. The consumer is perhaps most aware of taste tests in the context of adverts based on taste test claims by soft drinks companies. For example, most people are aware of adverts that proclaim that in blind taste tests, more people prefer Pepsi to Coke. Somewhat similarly, several Diet Pepsi adverts have featured celebrities claiming superiority in the taste of Diet Pepsi over Diet Coke. This trend of highlighting the results of taste tests is also noticeable in the beer industry. For instance, in an intensive comparative advertising campaign in 1991, Coors claimed that 58 per cent of beer drinkers preferred its Extra Gold over Budweiser in taste tests. ${ }^{1}$ Expanding on the cola market example mentioned earlier, Pepsi introduced the Pepsi Challenge in 1975 and continued with this notion until recently with the Joy of Cola campaign in order to change consumers' preferences for their cola drink. $^{2,3}$ There are numerous other examples of taste tests in various product categories in different markets in the world. This paper presents a few examples that can represent the wide range of tests used by marketers for influencing consumer preferences eg a taste test conducted by Taco Bell with its Gordita against Burger King's Whopper;
Burger King's taste test of its fries against those of McDonald's; ${ }^{4}$ or Papa John's Pizza against Pizza Hut in the American market. ${ }^{5,6}$ In the European market, Smith's Crisps was tested in a taste test in Holland to identify brand preference against Crock. ${ }^{7}$ In England, Virgin Cola challenged both Pepsi and Coke to capture a notable market share in the cola market. ${ }^{8}$

Taste tests are also used for new product development and market testing. For example, Minute Maid orange soda was introduced to the Canadian market after a blind taste test. ${ }^{9}$ Labatt Breweries used a mix of a blind and non-blind taste test where customers were asked to state their preference for either Labatt X or Labatt $\mathrm{Y}$ in the Canadian market. ${ }^{10}$ An example from the Asian market involved the Campbell Soup Co. test of the Hong Kong market for its soups and using these tests as a predictor also for the Chinese market; ${ }^{11}$ the major purpose is to be able to identify consumers who can be targeted by the firm. Samples for taste tests range from small-sized in-house panels for planning product design to the large sizes in test markets which are representative of markets that firms want to target. ${ }^{12}$

Given the importance of this subject in real-life businesses, several academic studies have looked at the different perspectives of taste testing. Broadly these measurements of taste can be divided into two categories: perceptual discrimination tests and preference tests. $^{13}$

The focus of the former kind of test is to examine whether consumers can distinguish the taste of any one brand from that of others in the same product. In other words, the idea is to investigate consumers' abilities to sense the dissimilarities in taste between different brands. ${ }^{14}$ This is a relevant problem when a brand is being reformulated or a 
new brand is being developed. For instance, suppose a soft drink firm is evaluating a new drink that is sweeter than other brands. It is important for the firm to know if consumers can distinguish the taste of this brand from those of other brands.

The purpose of preference taste tests is to find out how the firm's brand is ranked with respect to other competitive brands. This question is also pertinent when a new brand is being designed or an existing brand is being reformulated. Typically such preference values are considered to be indicators of choices made by consumers in the market. Marketers, as evident from the examples provided earlier, use this type of taste test more commonly than the perceptual one.

It is clear then that with respect to taste testing, two factors dominate. One is the consumers' perceptions of the dissimilarity between brands and the other is their feelings of preference for each brand. Obviously, both perceptions and preferences should affect the firm's product marketing plans. Therefore, it is important for firms to understand better the relationship between them since each one represents a different type of consumers' assessment of the firm's product. In this study the effect of the relationship between perceptual and preferential taste discrimination is examined. This is done by bringing together these two types of consumers' product evaluations and utilising them to create perceptual maps. Such an analysis allows the authors to suggest how this relationship can be used to increase the effectiveness of competitive brand positioning and targeting strategies, and better to understand consumer choice. Rabino and Moskowitz rightly mention that in food products, interactions among several continuous product attributes are important in generating consumer choice. ${ }^{15}$ It is, however, not an easy task for marketers to understand how consumers mentally combine their feelings about different interacting taste attributes before choosing a brand.

The purpose of this study is to understand how perceptual and preference-based measures can provide vital complementary information that would be useful for managers making positioning, segmentation and targeting decisions. Hence blind and both perceptual and preference tests are used for the data.

Current academic work has looked at either perceptual only, preferential only, or sometimes both but in contexts quite different from the present one, for example to see which preconditions the other - should a preferential follow a perceptual analysis or not. ${ }^{16-18}$ There is little work, however, that has tried to uncover the latent competitive market structure that exists in consumers' minds. In sum, it is important to gain insight into the latent perceptual and preference-based mindset of consumers and examine how that might affect the competitive brand positions, in the context of taste tests. This issue is addressed by using perceptual and preference-mapping algorithms based on the family of multidimensional scaling techniques. Together, these two kinds of maps will identify the underlying orthogonal taste dimensions on the basis of which consumers distinguish between brands. It is interesting to note here that other researchers have lent support to the general concept of reducing (by using factor analysis) sensory attributes to a limited set of orthogonal variables. ${ }^{19}$

By using this approach the authors are able to get insights of managerial relevance - insights which are hard to get by using only perceptual or preferential data on taste testing. In addition to identifying dimensions, the maps will provide diagnostic information 
about the competitive intensities between brands and also identify potential introduction opportunities for new brands possessing certain combinations of different taste dimensions. Finally, these maps will indicate how consumer choice patterns are expected to change depending on where the brands are positioned on taste dimensions.

The conceptual arguments are supplemented by findings from an empirical taste-testing study. The preference judgment part of the empirical study is designed to capture violations of the 'Independence of Irrelevant Alternatives' (IIA) effect. Perceptual and preference mapping techniques of multidimensional scaling are employed to analyse the empirical data. The paper concludes by presenting hypothetical examples of the positioning of a new brand on a certain taste dimension. Although on first consideration it would appear to have a great potential for inducing consumer switching from a competitive brand, a closer look at the map will clearly indicate why this might not transpire. In sum, this research illustrates how taste judgments can be used to understand brand positioning and market segments, and thus predict consumer choices better.

\section{TASTE TESTS: RECENT RESEARCH AND MAJOR ISSUES}

The objective of this section of the paper is to discuss briefly the major findings from some key articles in the academic literature on taste testing. It is by no means an exhaustive review and is not meant to be. Rather, it provides a summary of some of the primary issues with respect to the link between perceptual and preferential taste discrimination. This summary also indicates some of the motivations for the empirical study. Discussed below are four studies representative of the academic research on perceptual and preferential taste tests.

A study ${ }^{20}$ examined the relation between perceptual and preferential discriminative ability in taste tests. It was found that while these two properties are related to one another, neither preconditions the other. This finding differs from earlier findings in the literature that perceptual discrimination is a precondition for preferential discrimination. From a managerial viewpoint then, it appears that it is important to examine how consumers' perceptual and preference judgments should affect marketing decision making (eg, for product positioning tasks) of the firm.

Another study ${ }^{21}$ empirically evaluated some design changes in perceptual discrimination tests. Results indicate that these changes increase the reliability of the tests at the cost of some increase in the task difficulty of respondents.

Although the same design changes are suggested for preference taste tests, these were not tested with empirical data. The author of that study hypothesises that the task difficulty level for respondents could be somewhat greater in the preference test scenario, and suggests the empirical evaluation of the same design changes on preference tests as an area for future research.

One research study ${ }^{22}$ found that in terms of discrimination ability in preference judgments, a paired comparison task is superior to a preference ranking task. The authors suggest, however, that a preference-ranking test might be appropriate when variety-seeking behaviour exists among consumers.

There are other disadvantages to using paired comparisons. First, with an increasing number of brands, the number of paired comparisons increases very 
Table 1: Blind vs. non-blind taste tests

\begin{tabular}{llll}
\hline Type of test & Useful for & Susceptible to & $\begin{array}{c}\text { Measurement and } \\
\text { operationalisation }\end{array}$ \\
\hline Blind & $\begin{array}{c}\text { Finding how taste affects } \\
\text { preferences } \\
\text { Non-blind (branded) } \\
\text { Fothing the overall reality } \\
\text { state of the market of } \\
\text { preferences } \\
\text { Identifying the effects of } \\
\text { non-taste factors on } \\
\text { preferences }\end{array}$ & $\begin{array}{c}\text { Not revealing the 'real' } \\
\text { market effect } \\
\text { Favourableness can be } \\
\text { affected by other } \\
\text { factors (eg, advertising) }\end{array}$ & $\begin{array}{c}\text { Paired comparison, } \\
\text { preference ranking } \\
\text { Paired comparison, } \\
\text { preference ranking }\end{array}$ \\
$\begin{array}{l}\text { Measuring the difference } \\
\text { between the non-blind } \\
\text { and blind pattern of } \\
\text { preferences }\end{array}$ \\
\hline
\end{tabular}

rapidly - thus considerably increasing the task complexity for the respondents. Secondly, several paired comparisons would not reflect how consumers would actually evaluate the situation when all brands are present in a market together. This is because the paired approach is unable to capture violations of the IIA effect that is common in consumer behaviour. For instance, three sets of paired comparisons between the three soft drink brands of Coke, 7UP and Pepsi would not reveal the nature of preferences in a market which has these three brands at the same time. Suppose Coke and 7UP were the only two brands in the market to begin with. If Pepsi is introduced into the market, it is very likely that it will draw disproportionately more market share from Coke than from 7UP. This is because Pepsi is more similar in taste to Coke than to 7UP. This kind of unequal drawing of shares (known as violation of the IIA effect) by a third brand cannot be captured in paired comparison data. On the other hand, IIA violations are very common in real life. In fact, even a triad-type comparison will not be able to capture IIA violations if the actual number of relevant brands in the market is greater than three.

The impact of branded $v s$. blind taste tests have been discussed in the literature. ${ }^{23}$ Consider an example from that paper. In a blind taste test, Diet Pepsi was preferred by 51 per cent of the subjects while Diet Coke was preferred by 44 per cent. In contrast, a branded taste test resulted in Diet Pepsi being preferred by 23 per cent with Diet Coke being preferred by 65 per cent. Several subjects did not have a preference. It is obvious that the brand effect increased the rating of Diet Coke by respondents. The branded test perhaps reflects reality more closely. On its own, however, it provides less useful diagnostic information to the manager than a blind taste test does. For instance, the favourable brand effect could be caused by a number of different factors such as exposure to an exciting television advert or to an attractive in-store point of purchase display and so on. The standard kind of branded taste test itself will not be able to reveal any such specific reasons for the brand effect; answers to such a question have to come from an entirely different set of experiments. The blind taste test on the other hand, provides clear information about how the taste of the products affects preferences or/and perceptions of similarity. This is not to imply that branded taste tests do not have value. Such non-blind tests indeed serve to approximate more closely the overall reality of the marketplace. Since this study focuses on 'taste' itself, however, a blind taste-test design was 
used. It should also be noted that both types of tests can be used in order to assess the impact of non-taste effects on preferences by examining the differences between the two test results (more details on this issue are provided in the section on managerial implications and recommendations). Table 1 summarises the similarities and differences between the different types of taste test measurements.

These recent studies and the discussions based on them as mentioned above lead us to the following general conclusions. First, perceptual

differentiation and preferential evaluation are clearly distinct concepts in the realm of taste testing. Secondly, a great deal of attention in the literature has focused on devising test formats which permit more reliable discrimination; some new designs have been empirically tested while others await future testing. Thirdly, strategic implications of different kinds (ie perceptual and preferential) of taste tests in terms of simultaneous impacts on brand positioning, market segmentation and targeting, have not been explored much in the academic literature. This study is designed to investigate such strategic decision-making implications of taste testing.

\section{PRESENT STUDY}

The taste test study was conducted with a sample of respondents who were all business students in a major university.

The plan was to take the data from this sample and conduct multidimensional scaling (MDS) analysis. The sample characteristics therefore had to be compatible with the statistical requirements of the MDS analysis. The sample size used in the study is in accordance with the guidelines in the MDS literature. ${ }^{24}$ The guideline is that each object pair should preferably be judged by at least $M=40 \mathrm{~K} /(\mathrm{I}-1)$ subjects, where $\mathrm{K}=$ Number of map dimensions and $\mathrm{I}=$ Number of objects. For two dimensions and six objects (brands), this would give $M=16$. Thus there should be at least 16 subjects per data point. This study utilised 53 subjects per data point. The chosen product category was that of cola soft drinks. Soft drinks were selected since students were familiar with this product category. This familiarity with the class of soft drinks should lead to more accurate discrimination (both perceptual and preferential) between brands. Therefore any positioning or choice decision based on this study should be appropriate at least with respect to members of this sample.

Each subject tasted six different brands of colas. The order of presentation of these beverages was randomised to balance any cross-adaptation effects. ${ }^{25}$ The colas were each in separate paper cups and the subjects were not aware of the brand name for any of the soft drinks. A subject would taste a cola, then wash his/her mouth with water and then taste the second cola. The subject would then indicate on paper how similar in taste the two colas were. After washing their mouths with water again, a second pair of colas would be tasted and judged on similarity, and so on.

After similarity judgments were completed, subjects took part in preference taste tests. Here a subject would taste each of the six colas in succession before providing a preference ranking of the colas. The order of presentation of the drinks was again randomised across subjects. A subject was, however, allowed to taste a cola more than once, if he/she needed to do that to make a proper assessment. It was felt that this procedure would lead to a more reliable preference ranking, especially since a number of cola brands 
were involved. Subjects were, of course, instructed to always rinse their mouths with water before tasting a different cola brand.

As evident from the above descriptions, a subject made a set of similarity judgments and a set of preference judgments, based on blind taste. Since there are six cola brands, there are 15 paired similarity judgments in all for each subject. Similarity ratings were obtained on a 7-point rating scale where $1=$ Very Similar and $7=$ Very Dissimilar. Strictly speaking, therefore, these ratings were measures of dissimilarity between cola brands.

The preference judgments were in the form of overall preference ranks for the six colas. Preference ranking was favoured over the paired preference method, since the former method captures reality better in terms of reflecting violations of the IIA effect.

In sum, similarity judgments and preference ranking measures were obtained to indicate perceptual and preferential discrimination on the basis of taste testing.

\section{ANALYSIS}

The dissimilarity data in the form of a lower triangular proximity matrix was used as input to the $\mathrm{KYST}^{26}$

multidimensional scaling (MDS) program.

A non-metric MDS was run with Euclidean distances as the basis. A two-dimensional perceptual map was generated, providing 12 coordinates. A two-dimensional solution is appropriate (the following section provides interpretations of the dimensions) even though there were relatively few data values at the aggregate level. Observe, however, that the number of data values (even at the aggregate level) was greater than the number of coordinates indicating an acceptable solution. A similar situation is discussed by other researchers. ${ }^{27}$ It is to be also noted that the actual total number of data points in the study was 795 (ie 15 values times 53 respondents). Schiffman et al. specifically indicate that when the number of respondents is relatively large - ie ten or more (note: there were 53 in this study), it is quite reasonable to use a relatively smaller number of stimuli per dimension of a map. ${ }^{28} \mathrm{~A}$ two-dimensional solution led to the relevant perceptual map. A goodness of fit measure, $R_{m}^{2}$, was computed to evaluate the accuracy of the solution $R_{m}^{2}$ is the square of the product-moment correlation between the solution and the 'best' monotone transformation of the data. ${ }^{29}$ It represents the proportion of monotonically explained variance. $R_{m}^{2}$ can range from 0 to 1 . The authors' solution gave an $R_{m}^{2}$ value of 0.894 , indicating a very accurate visual representation of respondents' perceptions of the dissimilarity taste between cola brands.

In order to generate the preference map the PREFMAP ${ }^{30}$ unfolding MDS program was used. Input data to PREFMAP consisted of the preference ranking data of all the respondents and also the coordinates of the brand positions in the perceptual map (generated earlier by running KYST). A two-dimensional map again provided good interpretability and a high goodness of fit value; the latter indicated that the preference map was able to reflect the views of respondents very accurately.

\section{RESULTS}

\section{Perceptual mapping}

How similar or different are the perceived tastes of the different cola brands? This concept is visually represented in the perceptual map (Figure 1). This map indicates the 


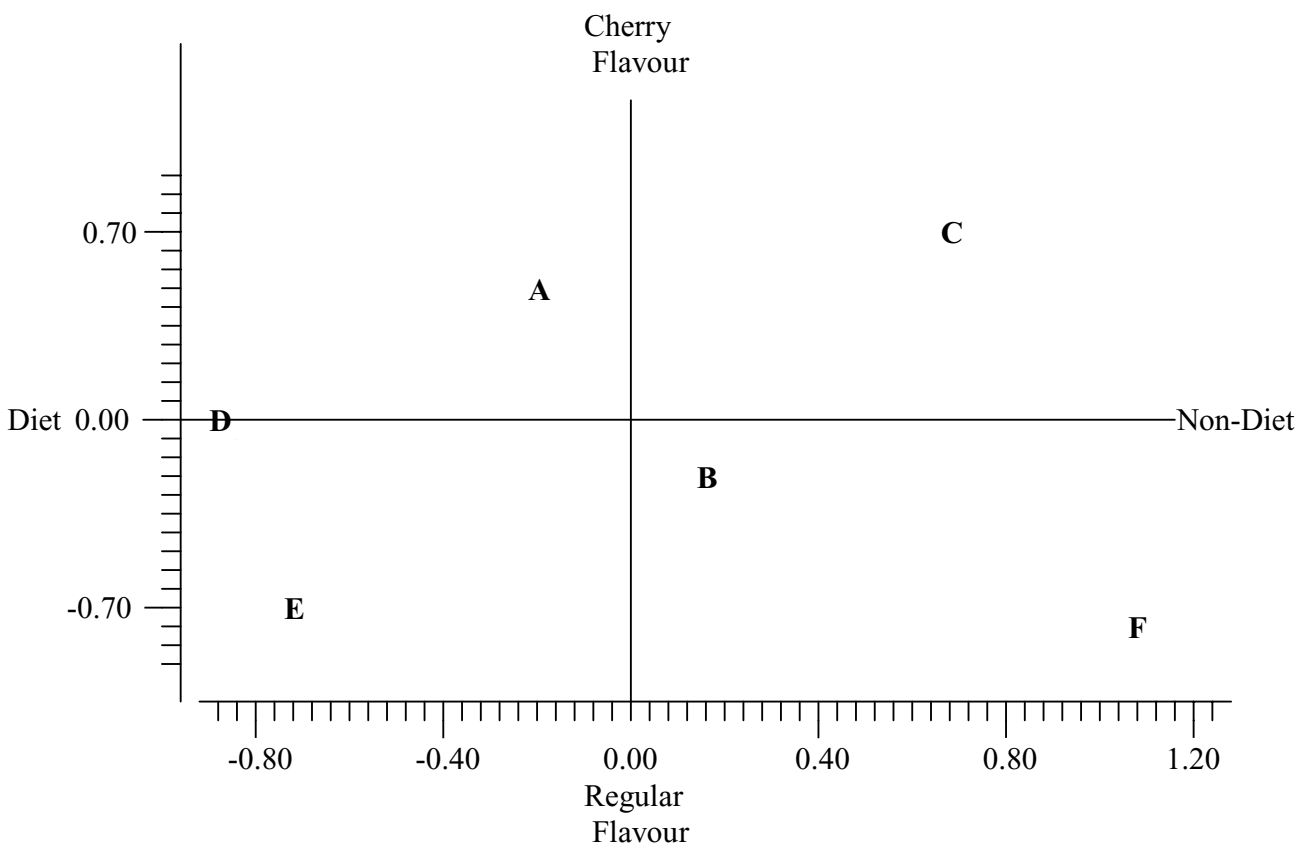

Figure 1 Perceptual map based on dissimilarity taste test of cola drinks

perceived positioning of the different brands. It is important for managers to understand the dimensions used by consumers to evaluate the different brands.

Figure 1 clearly indicates that the brand locations are quite different on the basis of each of the two dimensions separately. The six colas have been designated as brands A, B, C, D, E and F on the map. Brands B, C and F were non-diet colas and brands $\mathrm{A}, \mathrm{D}$ and $\mathrm{E}$ were diet colas. The horizontal dimension therefore separates the non-diet colas on the right from the diet colas on the left. Clearly, subjects were able to distinguish between the taste of diet and non-diet colas.

The vertical dimension appears to be a cherry flavour-regular flavour dimension. In this study, brand $\mathrm{C}$ was a non-diet cherry-flavoured cola while brand A was a diet cherry-flavoured cola. The other four colas had a regular flavour.
This perceptual map provides a substantial amount of information. First, it indicates that respondents distinguish the taste of the colas on two different taste dimensions: diet $v s$. non-diet flavour and cherry vs. regular cola flavour. Given that the researchers knew the actual characteristics of the six cola brands, it appears to be fairly evident that the respondents in the blind taste-test study were able to discriminate perceptually between the colas in the proper way. Secondly, the perceptual map indicates the degree of similarity in the overall taste between any two cola brands. The closer two brand points are to each other, the more similar in overall taste they have been perceived as being. For instance, brand $\mathrm{E}$ is more similar to brand $\mathrm{D}$ than to any of the other brands; $\mathrm{D}$ and $\mathrm{E}$ are both regular flavoured diet colas. Presumably, brand D competes most strongly with brand E. In a similar vein, brand $\mathrm{D}$ is perceived to be very 


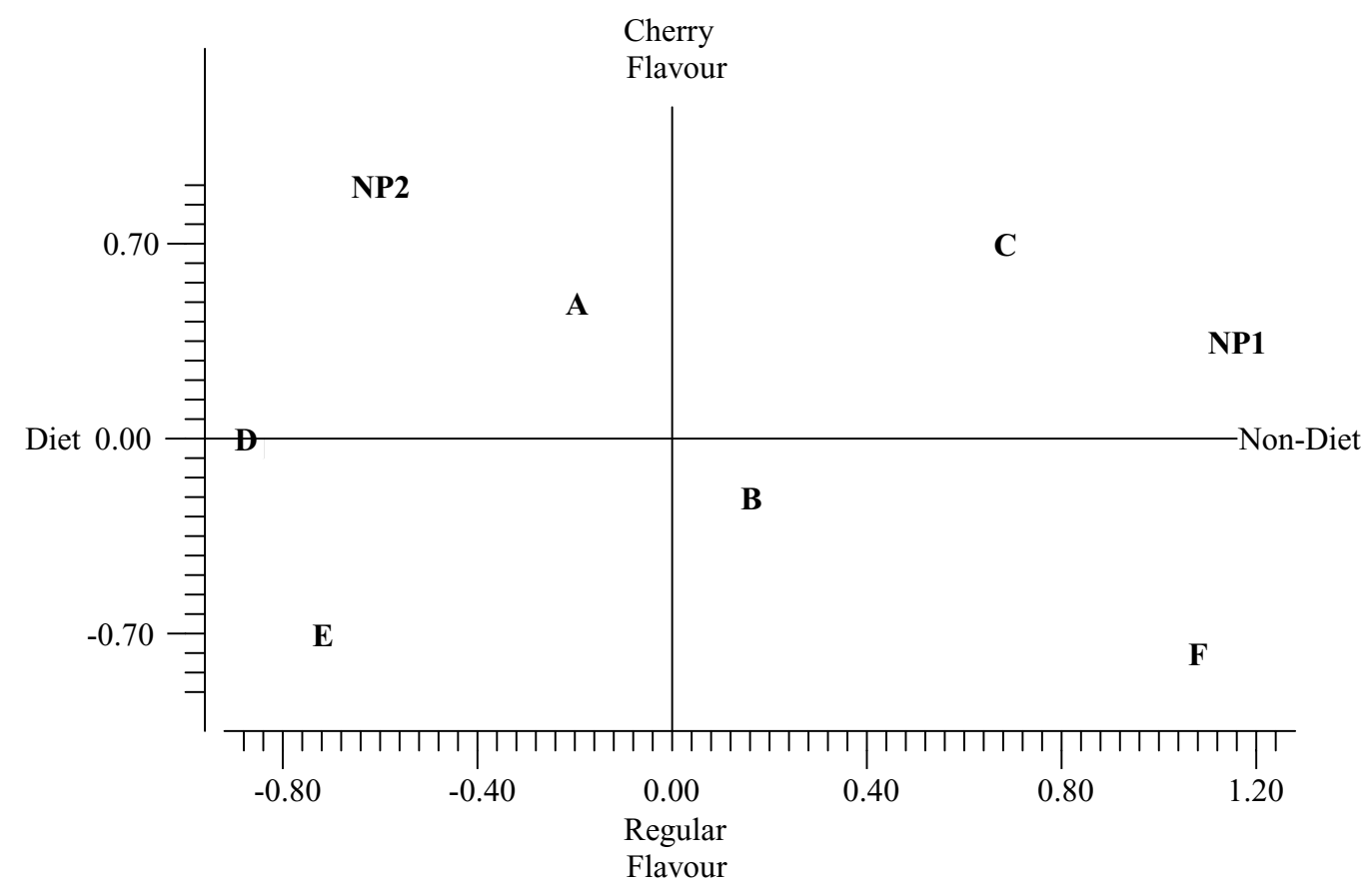

Figure 2: Perceptual map indicating some potential new product (NP) introduction opportunities

dissimilar in overall taste to brand F. A third kind of information available from this map is related to the positions of the brands with respect to the dimensions. For instance, while brands A, D and E are all diet colas, brand $\mathrm{D}$ has the strongest diet-drink like taste. Similarly, brand $\mathrm{F}$ has the most non-diet taste and the most non-cherry like flavour. A fourth important contribution of this perceptual map is that it shows existing gaps in the market, which a potential new brand could fill. For instance, NP1 and NP2 represent some of the available new product opportunities (see Figure 2) which could be seized by a firm to plug some of the gaps in the market.

Next the area of preference mapping is examined and relates it to the information available from perceptual mapping. In this way, the information on both perceptual and preferential discrimination that are intrinsic to consumer judgments of taste can be captured.

\section{Preference mapping}

What is the strategic impact of preferential taste discrimination? Answers to this question are available from the preference map (Figure 3) generated from the preference ranking data of the blind taste testing study and from the information about brand coordinates in the perceptual map.

This map shows two different sets of points: 1) the six cola brands and 2) the 'ideal points' of the respondents. Note that the relative configuration of brands in the preference map is in essence similar to that in the perceptual map. As in the case of the perceptual map, the brand locations in the preference map indicate several things. These include an estimate of the relative similarity between 


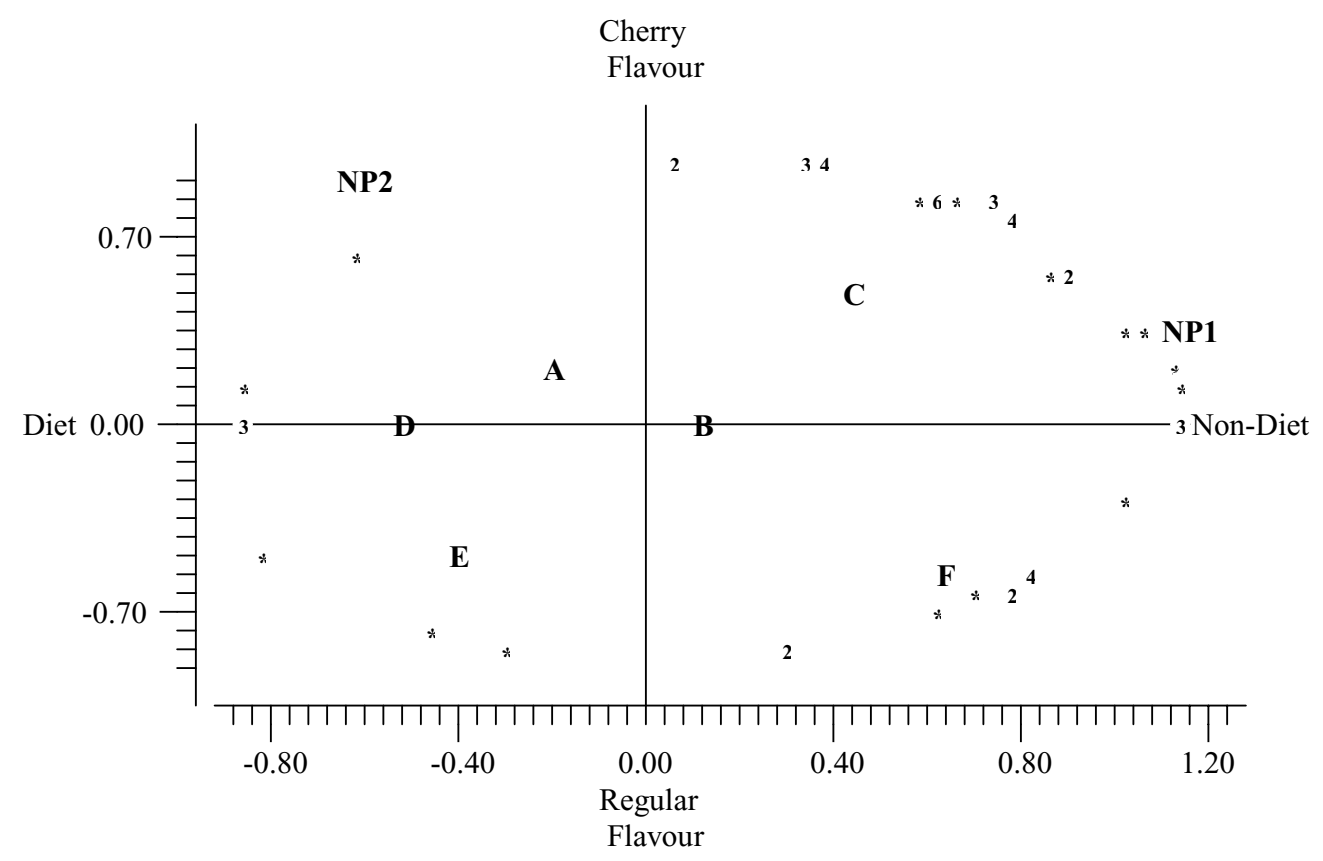

Figure 3: Preference map based on preference taste test of cola drinks Note: Asterisks and numbers on the map indicate 'ideal points' of respondents. An asterisk ( $\left(^{*}\right)$ indicates a single ideal point. A number indicates multiple ideal points (eg ' 4 ' indicates that four respondents share that location.

brand pairs, an indication of the extent of the two taste dimensions possessed by each brand and identification of gaps where no brands now exist. In addition, the preference map indicates what amounts of the two taste attributes must be present in a cola drink for it to be considered as 'ideal' by a given respondent. The map has many such ideal points - one for each of the respondents. In other words, the ideal point represents the most desired taste combination (of the regular/cherry flavour attribute and the non-diet/diet taste attribute) for a respondent. Clearly, therefore, an actual brand that is closest to a respondent's ideal point will be chosen by him (her).

The perceptual map (Figure 2) identified two gaps in the market which were both candidates for new product introductions (NP1 and NP2). The preference map indicates how much relative benefit a firm can earn by filling each gap. It is clear from the preference map (Figure 3) that the concentration of ideal points is much higher in the NP1 gap than in the NP2 gap. This means that far more respondents are favouring non-diet cola drinks and are likely to prefer a new brand that is strategically positioned in the NPl gap than if a new brand were to be positioned in the NP2 gap. Based on this study, this would indicate that a new non-diet cherry flavour cola would be a better bet for a firm (considering a new brand introduction) than a new diet cherry flavour cola from the perspective of targeting new consumers.

\section{Results summary}

The map based on the perceptual discrimination taste test identified the two basic taste dimensions to be diet $v s$. non-diet flavour and cherry vs. regular flavour. The cola brands had clearly 
distinct positions on these dimensions. Since the researchers knew what the actual brands were, it was possible for them to confirm that the respondents performed capably in the perceptual discrimination measurement task. The map based on the preferential discrimination measurement task indicated how different respondents prefer different combinations of the two taste attributes in a cola drink. Perceptual and preference maps each provide useful information which are complementary to one another.

The purpose of the study is to illustrate how perceptual and preferential data from taste tests can be used in a complementary manner to support brand positioning decisions so as to best match consumer needs. The actual results obtained in this study are clearly specific to this sample. The familiarity of the subjects with the product category lends some additional real-life validity to the pattern of the results. The real-world manager can easily gather data from a larger sample more representative of the market he/she is interested in. The basic usefulness of the overall approach suggested in this paper will, however, remain unaffected.

\section{MANAGERIAL IMPLICATIONS AND RECOMMENDATIONS}

Taste tests are an integral part of the activities in different industries. Not only are they used for product formulation but also for designing appropriate advertising copy as part of a company's targeting strategy. The soft drink industry is known to be one of the heavy users of taste tests.

Past academic studies have focused primarily on methodological issues of taste tests. Much less attention has been paid to the implications that perceptual and preferential taste tests together have on marketing decision making. The present paper uses advanced perceptual and preference mapping analyses to illustrate the complementary roles that perceptual and preference taste tests can play in supporting brand positioning, targeting and market segment identification decisions.

A common task of marketing managers is to understand how consumers perceive the firm's brand with respect to brands of competitors. This involves several different kinds of interrelated information. Managers want to know the underlying product dimensions on which brands compete, estimate the degree of competitive intensity between brands, identify gaps where no brands exist, and predict the effect of new brand introductions on consumer choice and hence on sales. In product categories where taste is one of the major reasons for brand choice, the manager's task is even more complex. This is because 'taste' is in many ways, an intangible attribute that can be properly judged not by objective measurement but by actual tasting by consumers. Maps based on consumer judgments of taste can convey the complex interrelationship of information to the marketing manager in an accurate and easily interpretable form. In Table 2 the similarities and differences between the preference and perceptual-based maps and their usefulness for different marketing tasks are summarised.

When the marketer's objective is to understand the impact of 'taste' alone on consumer perceptions and preferences of brands, blind taste tests followed by map generation are recommended. A non-blind test will also yield data on consumers' perceptions and preferences. It will be, however, very difficult to isolate whether the basic product attribute of taste or other factors like brand image and advertising are the 
Taste tests: Impacts of consumer perceptions and preferences on brand positioning strategies

Table 2: Perceptual vs. preferential mapping

\begin{tabular}{|c|c|c|c|c|}
\hline Type of map & Purpose & $\begin{array}{l}\text { Diagnostic } \\
\text { information }\end{array}$ & Useful for & Data \\
\hline Perceptual & $\begin{array}{l}\text { Finding how similar } \\
\text { are the perceived } \\
\text { tastes of different } \\
\text { brands }\end{array}$ & $\begin{array}{l}\text { Degree of similarity } \\
\text { in overall } \\
\text { assessment of } \\
\text { brands } \\
\text { Positioning of } \\
\text { brands and gaps } \\
\text { in the market }\end{array}$ & $\begin{array}{l}\text { Brand repositioning } \\
\text { New brand } \\
\text { introduction }\end{array}$ & Paired comparison \\
\hline Preferential & $\begin{array}{l}\text { Finding how } \\
\text { different are the } \\
\text { preferences of } \\
\text { different } \\
\text { combinations of } \\
\text { taste attributes }\end{array}$ & $\begin{array}{l}\text { The amount and } \\
\text { combination of } \\
\text { taste attributes to } \\
\text { be considered } \\
\text { ideal }\end{array}$ & $\begin{array}{l}\text { New brand } \\
\text { introduction } \\
\text { Brand reformulation }\end{array}$ & Preference ranking \\
\hline $\begin{array}{l}\text { Perceptual and } \\
\text { preferential }\end{array}$ & $\begin{array}{l}\text { Finding what is the } \\
\text { competitive } \\
\text { intensities } \\
\text { between brands }\end{array}$ & $\begin{array}{l}\text { Relative similarity } \\
\text { between brands } \\
\text { Segments of ideal } \\
\text { points } \\
\text { Positioning of } \\
\text { brands and their } \\
\text { distance to ideal } \\
\text { points }\end{array}$ & $\begin{array}{l}\text { Brand repositioning } \\
\text { New brand } \\
\text { introduction } \\
\text { Segmentation } \\
\text { Targeting }\end{array}$ & $\begin{array}{l}\text { Both paired } \\
\text { comparison and } \\
\text { preference } \\
\text { rankings }\end{array}$ \\
\hline
\end{tabular}

primary causes for the obtained pattern of consumer judgments. A properly conducted blind taste test will unambiguously identify the impact of taste on brand perceptions and preferences. This will greatly help in the task of brand (eg for soft drinks) formulation and customer targeting.

If the firm is interested in learning about the effects of other factors (eg advertising, brand image, brand loyalty) on consumer judgments, it is recommended that both blind and non-blind tests be conducted. The difference in the pattern of perceptual (and preference) maps between the non-blind and the blind taste tests will yield an idea of the impact of such other factors on brand positioning and choice.

The traditional perceptual and preferential discrimination studies will only yield information about taste discrimination between brands. Using maps, in addition, will enable managers also to identify the different fundamental attributes on the basis of which overall taste judgments are made. For the soft drinks in this study, the two attributes contributing to overall taste were diet $v s$. non-diet flavour and cherry $v s$. regular flavour. These two dimensions make perfect sense, given the specific stimuli used in the study. Therefore it appears that student subjects who are not taste testing 'experts' were able to discriminate between the brands appropriately in terms of taste.

Even among diet brands, for instance, a map indicates which brand has a stronger diet-drink like taste. Such fine distinction between brands will be of assistance to the firm when it plans to modify the formulation of a soft drink brand for a better repositioning and targeting strategy.

For preference taste tests, it is recommended that the preference ranking method be employed. This is because unlike paired comparisons, it captures violations of the IIA effect - a phenomenon common in real-life consumer behaviour.

Identification of taste dimensions, brand positions, and ideal points of 
consumers can provide a useful support mechanism for managers conducting product planning or designing an advertising strategy aimed at more effectively targeting different market segments. Consider some of the several options that are available. First, the firm's brand can be shifted towards an ideal point position. This can be achieved either by product reformulation or even by advertising. This will increase the likelihood of purchase of that brand by the single consumer represented by the ideal point. Judiciously shifting the firm's brand towards a larger cluster of ideal points will of course increase the overall sales of the brand, given other things constant. Secondly, it is possible for a firm to use adverts to shift a competitive brand away from the ideal point.

Arguably the advert message in this case has to be designed so as not to breach ethical or legal considerations. A third option would be to try and use advertising to shift the ideal point itself towards the firm's brand. Let us consider a hypothetical example of this option. An advertising campaign might keep highlighting the fact that the 'young generation' prefers a cherry flavour in their cola drink. Consider a viewer who strongly identifies himself with the 'young generation'. It is likely that his ideal point will shift in the direction of cherry even if he was more inclined to favour a regular flavour previously. This should increase the likelihood of his choosing a properly positioned cherry-cola brand belonging to the firm.

As stated earlier, maps aid the firm in planning the design and targeting strategy of a brand that is optimally positioned with respect to competitive brands and consumer ideal points. Once the brand is manufactured, subsequent taste tests followed by the generation of maps again would indicate to the firm whether the desired position has actually been achieved by the new (or reformulated) brand or not. The impact of formulation change on taste and hence on brand position can thus be verified.

Let us consider a hypothetical example to illustrate the important and complementary roles of similarity and preference judgments of tastes. Figure 4 shows a map with two competitive soft drink brands $\mathrm{X}$ and $\mathrm{Y}$; assume that the vertical dimension represents sweetness of the brand. $\mathrm{X}$ is thus sweeter than $\mathrm{Y}$. Suppose market research reveals that many people in a target segment prefer their soft drink to be quite sweet. Now if the firm which markets brand $\mathrm{Y}$ wants to introduce a new soft drink brand $\mathrm{Z}$, it would seem to make sense to make $Z$ a sweeter drink than $Y$. That is, $Z$ should be more similar in sweetness to $X$ than to Y. Figure 5 shows a map with $\mathrm{Z}$ occupying exactly such a position. Points other than $\mathrm{X}, \mathrm{Y}$ and $\mathrm{Z}$ in Figure 5 indicate the positions of ideal points of consumers. It is very interesting to note that even though $\mathrm{Z}$ is very similar to $\mathrm{X}$ in sweetness, few if any consumers will switch from $\mathrm{X}$ to $\mathrm{Z}$. This is because the relevant ideal points are all closer to $X$ than to $\mathrm{Z}$.

What the above hypothetical example shows is that similarity judgments are needed to identify existing brand positions but the manager also needs to know the exact relative location of the ideal points (obtained from preference data and data on brand coordinates in a perceptual map). Only then can one get a proper idea of expected purchase behaviour of consumers. Note that Figure 5 exaggerates (simply for the sake of illustration) this phenomenon by showing that absolutely no one will switch from $\mathrm{X}$ to $\mathrm{Z}$. It is essential, however, to appreciate that a somewhat inaccurate positioning of $\mathrm{Z}$ could lead to a significantly lower than expected amount of switching from $\mathrm{X}$ to $\mathrm{Z}$; 


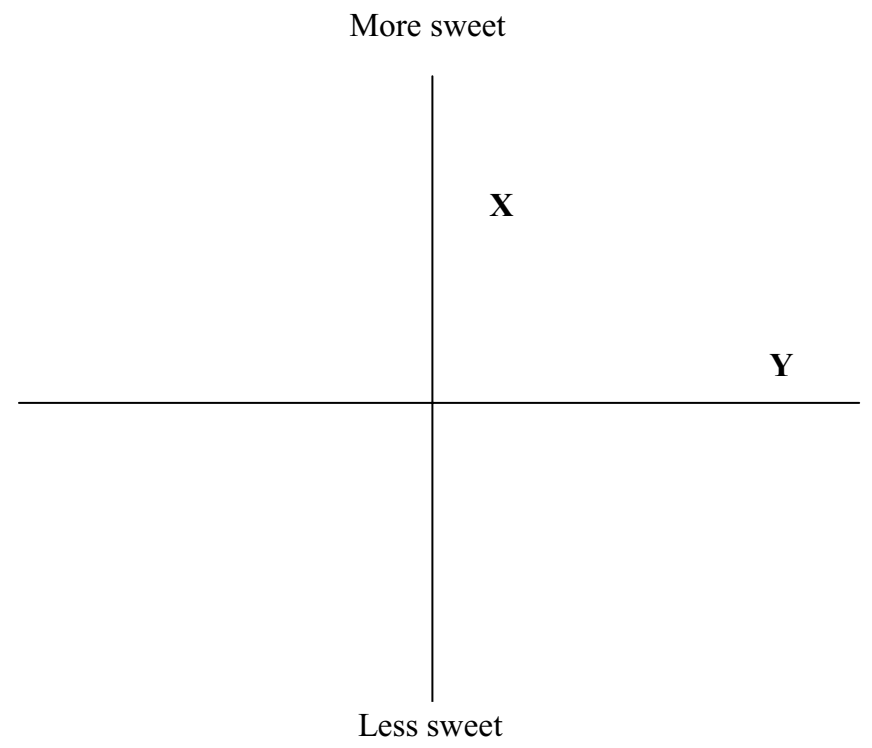

Figure 4: $A$ hypothetical soft drink market with brands $X$ and $Y$ (consumer ideal points not shown)

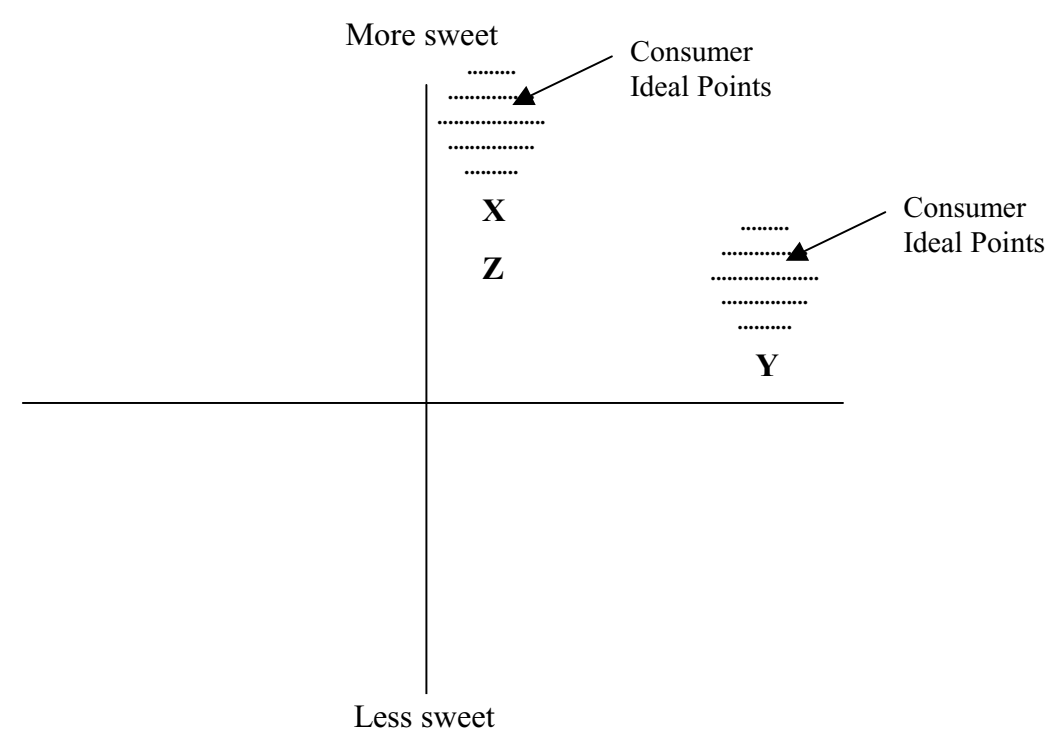

Figure 5: A hypothetical soft drink market with brands $X, Y$ and $Z ; Z$ is a new brand (consumer ideal points shown)

clearly the ramifications of this on the market share of $\mathrm{Z}$ will be quite serious.

It is also evident that maps-based preference-perceptions analyses would be useful for making better targeting decisions. That is, such analysis techniques can aid in better evaluation and identification of segments and their sizes in the market. Knowing the competitive position of the current brands and the perceptions of the consumer clusters, marketers can efficiently target the market segments most likely to be responsive to the firm's marketing strategies. For illustration, consider and continue with a variation of 


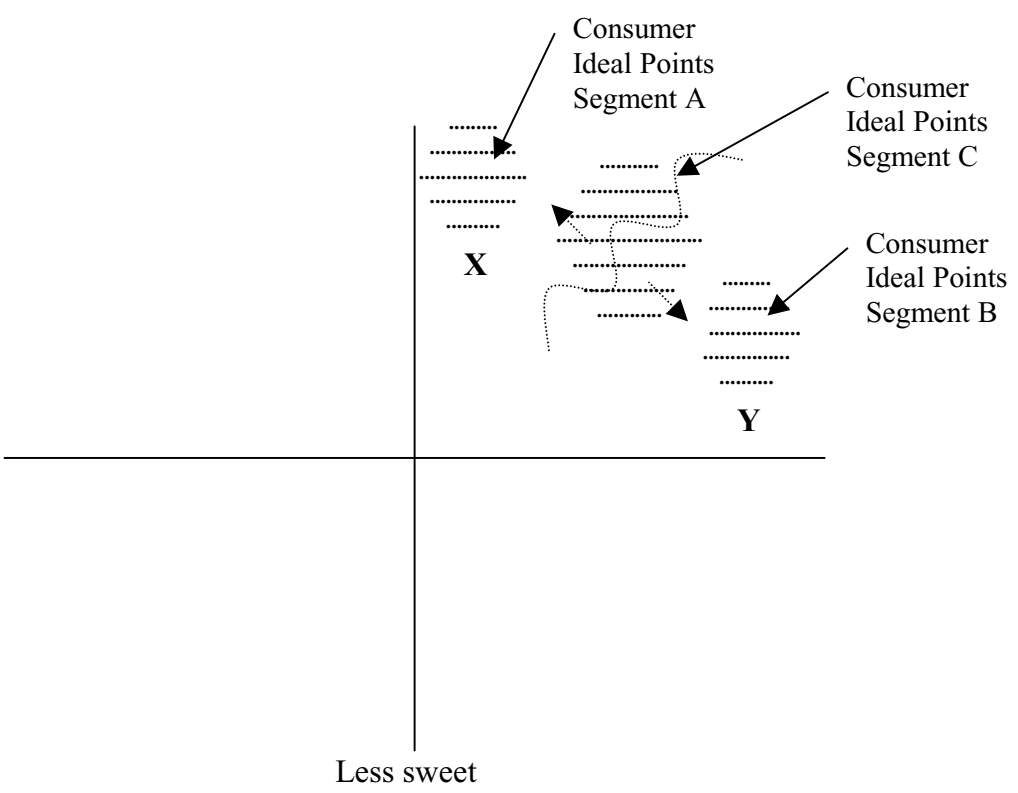

Figure 6: A hypothetical soft drink market with three segments and with brands $X$ and $Y$ (consumer ideal points shown)

the previous hypothetical example of a market described in Figure 5. Consider specifically a case of three segments, A, $\mathrm{B}$, and $\mathrm{C}$ with two brands, $\mathrm{X}$ and $\mathrm{Y}$, as depicted in Figure 6. The current state of this market is such that brand $\mathrm{X}$ is close to the ideal points of segment A, brand $\mathrm{Y}$ is close to the ideal points of segment $\mathrm{B}$. Consumers belonging to segment $\mathrm{C}$ do not have a brand that satisfies most of their needs (neither $\mathrm{X}$ nor $\mathrm{Y}$ are close to their ideal points). Thus, they will have to settle for either $\mathrm{X}$ or $\mathrm{Y}$ and this segment will probably be divided in a way as presented in Figure 6 with the arrows showing the migration of consumers to the distant brands. Figure 6 can provide marketers with insight as to the targeting and positioning strategies that firms could employ. First, marketers can identify the size of each segment. In the example, it can be seen that the largest segment is C. Secondly, they can identify 'holes' in the market. This would lead the firm to identify segments that do not have a brand close to their ideal points. Continuing with the example, a new brand $\mathrm{Z}$ can be developed that will have a combination of the two taste dimensions that will be close to those of the ideal points of segment C.

In sum then, both similarity based and preference based taste measurements have their own importance. Data from these tests when used in conjunction with perceptual and preference mapping analyses, provide a very robust decision-support mechanism to the marketing manager. Information from these maps is not only accurate but is also easy to understand. It is expected that positioning, targeting and segmentation decisions for products in which taste is a primary attribute, will benefit from the implementation of the proposed taste test-mapping analysis mechanism. Information based on taste-test maps should consequently help marketing managers to better understand consumers' perceptual competitive market structure and to 
Taste tests: Impacts of consumer perceptions and preferences on brand positioning strategies

make improved predictions about consumer choice.

\section{References}

1 Prince, G. (1991) 'Confrontation, innovation, gimmickry mark first month of new year's advertising', Beverage World, Vol. 110, No. 1483, 31 January, pp. 1-3.

2 Garfield, B. (2000) 'Pepsi may win challenge but loses most crucial test', Advertising Age, Vol. 71, No. 12, 27 March, p. 73.

3 Howard, T. (2000) 'Pepsi fires up challenge, "Joy" ads as bottlers reply: This ain't no Hawaii', Brandweek, Vol. 41, No. 13, 27 March, p. 6.

4 Cebrzynski, G. (1998) 'Taco Bell ad: Gordita whips the Whopper', Nation's Restaurant News, Vol. 32, No. 29, 20 July, p. 3.

5 Ibid.

6 Zuber, A. (1998) 'Papa John's takes on Pizza Hut, plans for growth', Nation's Restaurant News, Vol. 32, No. 13, 30 March, pp. 65-66.

7 Gibson, L. (1998) 'Crisp wars', Marketing Research, Vol. 10, No. 1, Spring, pp. 10-11.

8 Prince, G. (1996) 'Like a cola: Virgin flies high into US, but are its expectations in the clouds?', Beverage World, Vol. 115, No. 1624, 30 September, p. 1.

9 Brennan, L. (1986) 'Why Canada took to Minute Maid Orange Soda', Sales and Marketing Management, Vol. 136, No. 4, 10 March, pp. 99-105.

10 Barrington, S. (1995) 'Labat vote lets Canada canvass its tastebuds', Advertising Age, Vol. 66, No. 14, 3 April, p. 12.

11 Engardio, P. (1993) 'Hmm. Could use a little more snake', Business Week, No. 3309, 15 March, p. 53.

12 Moskowitz, H. R. (1985) 'New directions for product testing: and sensory analysis of foods', Food and Nutrition Press, Inc, Westport, CT.

13 Batsell, R. R. and Wind, Y. (1979) 'Product testing: Current methods and need developments', Journal of the Market Research Society, Vol. 22, No. 2, pp. 115-137.

14 Buchanan, B. and Henderson, P. W. (1992) 'Assessing the bias of preference, detection, and identification measures of discrimination ability in product design', Marketing Science, Vol. 11, No.1, Winter, pp. 64-75.
15 Rabino, S. and Moskowitz, H. R. (1984) 'Detecting buyer preferences to guide product development and advertising', Journal of Product Innovation Management, Vol. 1, No. 3, September, pp. 140-150.

16 Givon, M. M. and Goldman, A. (1987) 'Perceptual and preferential discrimination abilities in taste tests', Journal of Applied Psychology, Vol. 72, No. 2, pp. 301-306.

17 Buchanan, B., Givon, M. and Goldman, A. (1987) 'Measurement of discrimination ability in taste tests: An empirical investigation', Journal of Marketing Research, Vol. 24, May, pp. 154-163.

18 Givon, M. M. (1989) 'Taste tests: Changing the rules to improve the game', Marketing Science, Vol. 8, No. 3, Summer, pp. 281-290.

19 Moskowitz, H. R. and Jacobs, B. E. (1989) 'Using in-market products to generate target sensory profiles in early stage development', in Wu, L. S. (ed) 'Product testing with consumers for research guidance', American Society for Testing and Materials, Philadelphia.

20 Givon and Goldman (1987) op. cit.

21 Givon (1989) op. cit.

22 Buchanan, Givon and Goldman (1987) op. cit.

23 DeChernatony, L. and Knox, S. (1990) 'How an appreciation of consumer behavior can help in product testing, Journal of the Market Research Society, Vol. 32, No.3, pp. 329-347.

24 Davidson, M. L. (1983) 'Multidimensional scaling', John Wiley and Sons, Inc.

25 Welch, J. L. and Swift, C. O. (1992) 'Question order effects in taste testing of beverages', Academy of Marketing Science, Vol. 20, No. 3, pp. 265-268.

26 Kruskal, J. B., Young, F. W. and Seery, J. B. (1973) 'How to use KYST, a very flexible program to do multidimensional scaling and unfolding', Bell Laboratories, Murray Hill, NJ.

27 Schiffman, S. S., Reynolds, M. L. and Young, F. W. (1981) 'Introduction to multidimensional scaling: Theory methods and applications', Academic Press Inc, New York.

28 Ibid.

29 Pruzansky, S., Tversky, A. and Carroll, J. D. (1982) 'Spatial versus tree representations of proximity data', Psychometrika, Vol. 47, pp. 3-24.

30 Chang, J. J. and Carroll, J. D. (1972) 'How to use PREFMAP and PREFMAP2-Programs which relate preference data to multidimensional scaling solution', Bell Laboratories, Murray Hill, NJ. 